\title{
Unión entre marxismo y cristianismo en el Ejército de Liberación Nacional
}

Union between marxism and christianity in the National Liberation Army

Geraldine Bustos Zamora*

Resumen: El ingreso de Camilo Torres Restrepo al Ejército de Liberación Nacional (ELN), supuso la alianza entre dos visiones que se consideraban antagónicas en una guerrilla: marxismo y cristianismo. A partir de un estudio de carácter cualitativo se pretende analizar la unión entre el marxismo y el cristianismo en el ELN en el periodo de 1986 a 1989. Se sostiene que la unión se da mediada por el simbolismo creado alrededor de la figura de Camilo Torres que se manifestó en la promoción de un vínculo posible, e incluso obligatorio, entre cristianos y marxistas en las filas de la organización guerrillera en los últimos años de la década de los ochenta.

Palabras clave: conflicto armado, guerrilla, religión, Camilo Torres Restrepo, marxismo, utopía, cristianismo

\begin{abstract}
The entrance of Camilo Torres Restrepo to the National Liberation Army (ELN), supposed the alliance between two visions that were considered antagonistic in a guerrilla organization: Marxism and Christianity. Based on a qualitative study, this research aims to analyze the union between Marxism and Christianity in the ELN in the period from 1986 to 1989. It is argued that the union is mediated by the symbolism created around the figure of Camilo Torres that it manifested itself in the promotion of a possible, and even obligatory, link between Christians and Marxists in the guerrilla organization in the late 1980s.
\end{abstract}

Keywords: Armed conflicts, guerrilla, religion, Camilo Torres Restrepo, marxism, utopia, christianity

Recibido: 13 abril 2019 Aceptado: 23 agosto 2019

* Colombiana. Politóloga, Universidad de La Sabana. Estudiante de la Maestría en Estudios Políticos de la Universidad Nacional de Colombia. Profesora de la Universidad de La Sabana, integrante del grupo de investigación Res Publica. Este artículo de investigación hace parte del proyecto DER-53-2017 “La paz asediada. Discursos religiosos y violencia política en Colombia" financiado por la Universidad de La Sabana. Fecha inicio proyecto: 26/01/2018. Fecha terminación proyecto: 26/01/2021. Correo: geraldine.bustos@unisabana.edu.co 


\section{Introducción}

La guerrilla del Ejército de Liberación Nacional (ELN) nació en 1964 en la región del Magdalena Medio del departamento de Santander, Colombia, en los municipios de San Vicente de Chucurí y Barrancabermeja1. Formada en sus inicios por campesinos y estudiantes de la Universidad Industrial de Santander², que, inspirados por las ideas de la Revolución cubana, promovían una política nacionalista y anti oligárquica ${ }^{3}$.

Uno de los rasgos característicos y distintivos del ELN, fue el ingreso del sacerdote bogotano Camilo Torres Restrepo a sus filas en 1965. La entrada de Camilo Torres a la organización marcó el punto de partida en las relaciones entre marxismo y cristianismo revolucionario en el país y en el continente, pues Torres fue el primer sacerdote católico en ingresar a una guerrilla marxista. Frente a ese punto, Alejo Vargas sostiene que la vinculación de Camilo Torres tiene dos impactos centrales en el ELN, primero, "su figura legitima en cierta forma a la naciente guerrilla" 4 y segundo "en la aproximación a las corrientes de cristianos críticos que se van a desarrollar posteriormente, influidas por el sacerdote, quien es indudablemente pionero en este campo" 5 . También Carlos Medina Gallego resalta en sus estudios la idea de que en el ELN se desarrolló una mística revolucionaria en la que el sacrificio fue el puente entre católicos y marxistas, lo que permitió vivir dentro de la organización la máxima de liberación o muerté.

Oscar Pedraza en su texto El ejercicio de la liberación nacional: ética y recursos naturales en el ELN, destaca que la apuesta realizada por el ELN al levantar la figura de Camilo Torres, en la medida que

Reconoce la importancia de un aspecto que históricamente para la izquierda se había perdido pero que en América Latina venía cobrando importancia. La religión, como fenómeno constitutivo de la sociedad y cultura latinoamericanas, no puede simplemente desligarse de los objetivos políticos y sociales de cualquier organización. En esa medida, el ELN considera importante revitalizar la figura y el

1 Carlos Medina, ELN: Ejército de Liberación Nacional: cincuenta años de lucha armada, Bogotá, Universidad Nacional de Colombia, 2014.

2Mario Aguilera, "ELN entre las armas y la política”, Gonzalo Sánchez, María Wills y Francisco Gutiérrez (coord.), Nuestra guerra sin nombre: transformaciones del conflicto en Colombia, Bogotá, Grupo Editorial Norma, 2006, 209-266.

3 Carlos Medina, Ejército de Liberación Nacional (ELN): Historia de Las Ideas Políticas (1958-2018), Bogotá, Universidad Nacional de Colombia, 2019, P. 88.

4 Alejo Vargas, Guerra o solución negociada. ELN: origen, evolución y procesos de paz, Bogotá, Intermedio, 2006, P. 212

5 Vargas, op. cit., P. 213.

6 En la literatura sobre la historia del Ejército de Liberación Nacional se destacan los aportes de Carlos Medina Gallego con las obras: ELN: una historia contada a dos voces, entrevista con el cura Manuel Pérez y Nicolás Rodríguez Bautista, Gabino, Bogotá, Rodríguez Quito, 1996; “Aproximación a las ideas políticas del ELN", Corporación Observatorio para la Paz, Las verdaderas intenciones del ELN, Bogotá, Intermedio Editores, 2001, 120-157; Conflicto armado y procesos de paz en Colombia: memoria casos FARC-EP y ELN, Bogotá, Universidad Nacional de Colombia, 2009; ELN: Ejército de Liberación Nacional: cincuenta años de lucha armada, Bogotá, Universidad Nacional de Colombia, 2014 y Ejército de Liberación Nacional (ELN): Historia de Las Ideas Políticas (1958-2018), Bogotá, Universidad Nacional de Colombia, 2019. 
simbolismo de un militante de la organización y reconocer la importancia de un sector de la sociedad que dentro de los lineamientos de la izquierda carece de relevancia política, de alguna manera situado dentro de una caracterización superestructural de su identidad7.

Este trabajo busca a partir de un estudio de carácter cualitativo analizar la unión entre marxismo y cristianismo dentro del ELN en el periodo de 1986 a 1989, a partir de la revisión de fuentes primarias de la organización. Ese propósito se enmarca en las relaciones entre política y religión en el seno del grupo guerrillero, en el que los discursos en torno al sacrificio, la entrega, la construcción de íconos en sus filas, y la masiva presencia de sectores de la Iglesia dentro de la estructura militar hacen que sea pertinente revisar la unión entre dos visiones consideradas antagónicas. Se sostiene que la unión se dio a través de la figura de Camilo Torres Restrepo, quien fue reivindicado en la guerrilla 20 años después de su muerte en las conclusiones de la I Asamblea Nacional Comandante Camilo Torres Restrepo y el II Congreso Unión Camilista Ejército de Liberación Nacional, realizados en 1986 y 1989 respectivamente.

El sacerdote Camilo Torres Restrepo, apareció como una figura central, en el marco de la renovación de la Iglesia Católica en Colombia en la década de los sesenta, ingresó en 1965 a la guerrilla del ELN y tras morir en combate en 1966 "estremeció a la Colombia conservadurista de la época"8, se convirtió en un ícono del ELN, y en un representante de la violencia revolucionaria en el continente. Su condición de sacerdote guerrillero fue una prueba de la unión entre marxismo y cristianismo, teniendo como referencia la reivindicación de las relaciones entre esas dos corrientes antagónicas en el seno de la guerrilla, se pretende entonces responder a la pregunta sobre ¿Cómo se dio la unión entre marxismo y cristianismo en el periodo de 1986 a 1989 en el ELN?

En el presente artículo se utiliza un enfoque cualitativo a partir del estudio de fuentes primarias como lo son los documentos, las memorias y los archivos del ELN. Para tener un abordaje más amplio, también se tienen en cuenta fuentes secundarias. La investigación busca obtener a partir del análisis de las fuentes una mayor comprensión de un proceso social, como lo es la relación entre el cristianismo y el marxismo, a partir de lo que significó la figura de Camilo Torres como sacerdote católico que ingresó a una guerrilla marxista. En cuanto a la temporalidad se tienen en cuenta el desarrollo teórico del ELN en los Congresos de 1986 y 1989, en los cuales se discutió desde la dirección de la organización sobre la relación entre cristianos y marxistas.

El texto se divide en 3 apartados en la primera parte se discutirá sobre la relación entre marxismo y cristianismo, luego se discutirá sobre la figura de Camilo Torres Restrepo dentro del ELN, y posteriormente se revisará cómo fue la unión de elementos cristianos y marxistas en las conclusiones de la I Asamblea Nacional Comandante Camilo Torres Restrepo y el II Congreso Unión Camilista Ejército de Liberación Nacional.

Marxismo y cristianismo en el Ejército de Liberación Nacional

7 Oscar Pedraza, “El ejercicio de la liberación nacional: ética y recursos naturales en el ELN”, Controversia, 190, 2008, 197-241, P. 205

8 Alejo Vargas, "Conflicto armado, su superación y modernización en la sociedad colombiana”, Pensamiento jurídico, 26, 2009, P. 165. 
La unión entre el cristianismo y el marxismo jugó un papel determinante en la configuración de los movimientos revolucionarios en América Latina a partir de la década de los sesenta. Autores como Estrada \& Bataillon señalan que para las organizaciones revolucionarias de América Latina "el uso de la violencia fue una manera legítima de constituirse en actores sociopolíticos" ${ }^{\prime 9}$ estos dos autores introducen la categoría de cruzadas seculares para determinar la "manera en que cierto número de esquemas tomados del cristianismo, fueron reutilizados y modificados por los actores mismos para apuntalar su praxis"10. Jean-Pierre Bastian, va más allá en el desarrollo de la categoría de cruzadas seculares y explica las dimensiones religiosas de la acción revolucionaria, concluyendo que “existen elementos sociales y simbólicos comunes a la esfera religiosa y a la esfera políticorevolucionaria en América Latina [...] de ahí que el término cruzadas seculares para definir la acción revolucionaria en la región no sea contradictoria" 11.

La relación entre marxismo y cristianismo se enmarca en la relación entre religión y política, en la que el uso de argumentos religiosos por parte de grupos revolucionarios como el ELN, no se dio en una única dirección, sino que obtuvieron respuesta de sectores de religiosos, religiosas y laicos que consideraron que ser revolucionario estaba en concordancia con ser cristiano ${ }^{12}$. Así, por ejemplo, se observa en la teología de la liberación ${ }^{13}$ una evolución en los postulados teológicos que derivaron en un radicalismo revolucionario ${ }^{14}$. Estrada anota que en América Latina desde la década de los sesenta se dio una alianza entre las dimensiones simbólicas e ideológicas de los religiosos y los revolucionarios que derivaron en una política de la fe, que buscaba la construcción de una comunidad cristiano-política que reflejara el paraíso en la tierra15, la cual, para el caso del ELN, tuvo como base el llamado a vivir las enseñanzas del amor eficaz de Camilo Torres.

La Conferencia Episcopal Latinoamericana -CELAM- realizada en Medellín en el año 1968, le dio un impulso a los católicos que justificaban el uso de la violencia, toda vez que en las conclusiones del encuentro se pedía, entre otras cosas, "anunciar el estado de

\footnotetext{
9 Marco Estrada y Gilles Bataillon, “Introducción”, Marco Estrada y Gilles Bataillon (eds.), Cruzadas seculares: religión y luchas (anti) revolucionarias, Ciudad de México, Colegio de México, 2012, P. 10.

10 Ibidem.

11 Jean-Pierre Bastian, "Cruzadas seculares: imaginario religioso y luchas revolucionarias en América Latina", Marco Estrada y Gilles Bataillon (eds.), Cruzadas seculares: religión y luchas (anti) revolucionarias, Ciudad de México, Colegio de México, 2012, P. 31.

12 Esto se puede ver en Marco Estrada y Guilles Bataillon (eds.) Cruzadas seculares: religión y luchas (anti) revolucionarias, Ciudad de México, Colegio de México, 2012, en los capítulos de Malik Tahar, “Una expresión cristiana del radicalismo sociopolítico en América Latina: La teología de la liberación entre cruzada antisacrificial y el sacrificio crístico" y Jean-Pierre Bastian, "Cruzadas seculares: imaginario religioso y luchas revolucionarias en América Latina".

13 Sobre la teología de la liberación ver Victor Codina, "Teología de la liberación 40 años después. balance y perspectiva", Revista de Estudios de Teologia E Ciências Da Religião, 11, 2013; Fernán González, ¿Teología de la Liberación en el Siglo XIX?: El uso de la Religión Católica en las Discusiones en torno a la independencia y Antonio Echeverry, Teología de la Liberación en Colombia. Universidad del Valle, 2007.

14 Malik Tahar, "Una expresión cristiana del radicalismo sociopolítico en América Latina: La teología de la liberación entre cruzada antisacrificial y el sacrificio crístico", Marco Estrada y Gilles Bataillon (eds.), Cruzadas seculares: religión y luchas (anti) revolucionarias, Ciudad de México, Colegio de México, 2012, 35-54.

15 Marco Estrada, "Del apocalipsis al fin de la historia: Los agentes de pastoral y el EZLN en Chiapas",", Marco Estrada y Gilles Bataillon (eds.,), Cruzadas seculares: religión y luchas (anti) revolucionarias, Ciudad de México, Colegio de México, 2012, 55-84.
} 
violencia en el cual los poderosos han sumido durante siglos los pueblos de nuestro continente y proclamar el derecho de esos pueblos a la legitima defensa"16. A su vez, en la Carta a los Obispos de América Latina reunidos en Medellín, un grupo de sacerdotes solicitaron que "en la reflexión sobre la violencia en América Latina, se evite por todos los medios comparar o confundir la violencia injusta de los opresores que son los sostenes de este "nefasto sistema" con la justa violencia de los oprimidos, que se ven obligados a recurrir a ella para obtener su liberación" 17 . Según Codina,

Los obispos en Medellín escucharon el clamor del pueblo pobre y oprimido, discernieron en este grito un signo de los tiempos y decidieron responder a este clamor y acompañar al pueblo en sus ansias de justicia y liberación de las estructuras de pecado, para pasar de condiciones inhumanas de vida a condiciones de vida más humanas y justas ${ }^{18}$.

A partir de las simbologías compartidas entre el marxismo y el cristianismo, como el sacrificio, la entrega, la consideración de una violencia injusta y el llamado a una iglesia popular, la religión en el ELN fue utilizada como un elemento cohesionador y de creación de valores comunes ${ }^{19}$ dentro de la tropa, que se materializaron en las conclusiones de la I Asamblea Nacional Comandante Camilo Torres Restrepo y el II Congreso Unión Camilista Ejército de Liberación Nacional, teniendo como eje articulador a Camilo Torres. Estos elementos contribuyeron a la mistificación de los caídos en combate, siendo un mecanismo que justificó y legitimó la continuación de la lucha armada. Pérez, señala como en el ELN coexisten el ejército regular de los vivos, con un ejército de los muertos ${ }^{20}$ en donde el compromiso con los caídos en combate y los más necesitados adquiere un sentido religioso cristiano ${ }^{21}$ a través del sacrificio.

Para los sectores más progresistas del clero y que veían en Torres una fuente de inspiración, su muerte demostró que "había que hacer una revolución para la revolución del amor eficaz, por tanto, buscaban entroncarse en un movimiento político que obedeciera a ese ideal que ellos tenían, lo que más se les acerca es el ELN"22, entre los curas rebeldes que siguieron el impulso de Torres destacan las figuras de los españoles Manuel Pérez, Domingo Laín y José Antonio Jiménez que ingresaron a las filas del ELN en la década del setenta.

El énfasis que se hace en los dos congresos del ELN sobre la entrega de Camilo Torres al ingresar a la guerrilla, pone de presente la justificación de la violencia y el desprecio de

\footnotetext{
16 Arias, op. cit., P. 209.

17 Obispos del Tercer Mundo. “Carta a los Obispos de América Latina”, Buenos Aires, Ediciones E.S.E, 1965, P. 70 .

18 Víctor Codina, “Teología de la liberación 40 años después. balance y perspectiva”, Revista de Estudios de Teologia E Ciências Da Religião, 11, 2013, P. 1359.

19 Andrea Pérez, “Tradiciones de Resistencia y Lucha: Un análisis sobre el surgimiento y la permanencia de las guerrillas en Colombia", Análisis Político, 23, 2010, 63-80.

20 Pérez, op. cit.

21 Pérez, op. cit.

22 Afirmó Javier Darío Restrepo en entrevista concedida al autor para el proyecto de investigación La paz asediada. Discursos religiosos y violencia política en Colombia, Bogotá, 25 de enero de 2017.
} 
los medios democráticos, lo que llevó a que se hiciera un llamado a los cristianos a considerar que no les quedaba otra opción sino la lucha armada, "fueron cientos de miles de jóvenes católicos en diferentes partes del mundo que pusieron su fe -como Camilo había puesto la suya- en un sueño, un nuevo estado de cosas, algo que llamaban La Revolución" 23. Un sueño, que se veía compatible con los postulados de la Teología de la Liberación y con el amor al prójimo, máxima del catolicismo, así en el II Congreso se expresa la necesidad de una respuesta, a lo que se denomina una violencia institucional, por parte de los cristianos revolucionarios que

Ven cómo los pobres luchan por conquistar sus derechos y se enfrentan contra la intransigencia de los explotadores. Al pueblo no le queda otra alternativa que levantarse en armas para conquistar su libertad, su bienestar, es una respuesta lógica del pueblo a una guerra que le ha sido impuesta. Y desde este punto de vista la violencia es legítima cuando se hace en defensa de todo un pueblo ${ }^{24}$.

Para consolidar la unión entre marxismo y cristianismo, en el ELN se partió de una visión en la que la lucha cobra sentido a partir de la entrega de la vida como la muestra más grande de amor por los amigos y por el pueblo ${ }^{25}$. Esa entrega se convirtió así en un elemento común entre cristianos y marxistas ya que se vista como un sacrificio, mediante el cual se pueden construir santos dentro de la organización ${ }^{26}$ como se observa en los casos de Ernesto Guevara ${ }^{27}$ y Camilo Torres dentro del ELN y en otros movimientos insurgentes de América Latina.

La simbiosis entre el cristianismo y la revolución se convirtió en un elemento común en la identidad de las organizaciones guerrilleras de América Latina y no debe reducirse a la participación de religiosos en las actividades guerrilleras, sino que también se debió la fuerte presencia de campesinos en las filas ${ }^{28}$. Según el también sacerdote Manuel Pérez, quien fue comandante del ELN desde 1974 hasta 1993, la relación entre el cristianismo y el marxismo y el aporte de los cristianos en la lucha armada se fundamenta en tres puntos, el énfasis de la persona humana como sujeto de la revolución, la participación de la persona en la construcción de su propio destino y en generar formas de organización como las comunidades eclesiales de base ${ }^{29}$. Broderick afirma que Manuel Pérez buscó en el ELN la unión entre el marxismo y el cristianismo siguiendo la figura de Camilo Torres Restrepo, ya que el sacerdote colombiano

\footnotetext{
23 Joe Broderick, Camilo Torres. El cura guerrillero, Bogotá, Círculo de lectores, 1977, P. 75.

24 Dirección Nacional Unión Camilista Ejército de Liberación Nacional [DN-UCELN], op. cit., P. 230.

25 Anaité Galeotti, “Un Jesús muy compañero. Un testimonio de liberación”, Marco Estrada y Gilles Bataillon (eds.,), Cruzadas seculares: religión y luchas (anti) revolucionarias, Ciudad de México, Colegio de México, 2012, 85-102.

${ }^{26}$ Gilles Bataillon, “Ernesto Guevara: Héroe revolucionario y apologista del poder ególatra”, Marco Estrada y Gilles Bataillon (eds.), Cruzadas seculares: religión y luchas (anti) revolucionarias, Ciudad de México, Colegio de México, 2012, 161-194.

27 Sobre la construcción de héroes en las organizaciones guerrilleras se puede ver, Mario Aguilera, "La memoria y los héroes guerrilleros." Análisis Político, 49, 2003, 3-27

28 Harnecker, ELN: Unidad que multiplica, La Habana, Banco Popular, 1988.

29 Ibid.
} 
Se fue convirtiendo en el ejemplo de la entrega y la convicción. Y de la encarnación que nosotros andábamos buscando. Porque había dado la vida, porque se había metido a todas, sin retroceso, sin vuelta atrás. En resumen, Camilo se había sacrificado ${ }^{30}$.

También, dentro del ELN, con la muerte de Camilo Torres se hizo un símil con la figura de Jesús como máxima de la salvación cristiana ${ }^{31}$, es decir, una versión de la muerte del sacerdote Torres Restrepo en combate fue una visión moderna del sacrificio de Jesús, en la medida que fue exaltado y puesto en el olimpo de los íconos de la revolución ${ }^{32}$.

Camilo Torres y el Ejército de Liberación Nacional

Camilo Torres Restrepo nació el 03 de febrero de 1929 en la ciudad de Bogotá. En 1946 ingresó al Seminario Mayor de Bogotá, se ordenó como sacerdote en 1954 y viajó a la Universidad de Lovaina para estudiar sociología. De regreso a Colombia trabajó en la Universidad Nacional como capellán y junto con Orlando Fals Borda fundó el departamento de sociología ${ }^{33}$. En su condición sacerdotal, Camilo Torres vivió la transformación de la Iglesia Católica de la década de los sesenta, producto del Concilio Vaticano II (1962-1965) y las conclusiones de la II Conferencia Episcopal Latinoamericana celebrada en Medellín en 1968. El sacerdote Torres movidos por las ideas conciliares buscó la promoción de una Iglesia renovada y moderna. Sin embargo, pese a los postulados del Concilio, en Colombia la jerarquía eclesiástica se opuso a las reorientaciones postconciliares ${ }^{34}$. Esta actitud de la curia colombiana le costó la aparición de figuras como Camilo Torres dentro de sus filas y de otros sacerdotes como René García y Monseñor Gerardo Valencia Cano, que buscaron vivir las reformas del Concilio, especialmente las relativas a la causa social de la Iglesia.

Sus postulados sobre el papel de los cristianos y del cristianismo en la sociedad, generaron una tensión entre él y la jerarquía de la Iglesia colombiana, en cabeza del Cardenal Luis Concha Córdoba 35 , como resultado de ese enfrentamiento, el sacerdote decidió pedir la reducción al estado laical36, e ingresó al ELN en 1965, según Arias

Torres simboliza una ruptura en la historia del catolicismo colombiano, por primera vez, un miembro del clero ingresa a un movimiento "revolucionario", y además marxista, con todo lo que ello significa: un

\footnotetext{
30 Joe Broderick, El guerrillero invisible, Bogotá, Intermedio, 2000, P. 76.

31 Victorino Pérez, "Richard Shaull, Camilo Torres, Rafael Ávila, "Golconda", Sacerdotes para América Latina, Cristianos por el Socialismo y Comunidades Eclesiales de Base", Cuestiones Teológicas, 43, 2016, 73-108.

32 Esto se puede encontrar en Aguilera, "La memoria y los héroes guerrilleros"; Arias, El episcopado colombiano: intransigencia y laicidad 1850-200 y Pérez, "Richard Shaull, Camilo Torres, Rafael Ávila, Golconda", Sacerdotes para América Latina, Cristianos por el Socialismo y Comunidades Eclesiales de Base".

33 Para más información biográfica sobre Camilo Torres ver Joe Broderick, Camilo Torres. El cura guerrillero, Hildergard Luning, Camilo Torres: sacerdocio y política Bogotá, Universidad Nacional de Colombia, 2016; Carlos Medina, Camilo Torres Restrepo: la sonrisa de la esperanza, Bogotá, Universidad Nacional de Colombia, 2017 y María López, Camilo camina en Colombia, Navarra, Txalaparta, 1990

34 Ricardo Arias, "El episcopado colombiano en los años 1960”, Revista de Estudios Sociales, 33, Bogotá, 2009, 7990.

35 Álvaro Tirado, Los años sesenta, Bogotá, Debate, 2014.

36 Germán Guzmán, La violencia en Colombia: Parte descriptiva. Cali, Ediciones El Progreso, 1968.
} 
nuevo referente que en adelante servirá de inspiración a otros católicos que ven en el ejemplo de Torres un paradigma ${ }^{37}$.

En una sociedad tradicionalmente católica como la colombiana la incorporación de Camilo Torres a las filas del ELN marcó un punto de inflexión en la época al mostrar como desde el sector que era considerado más conservador, también se hacía un llamado a la violencia ${ }^{38}$.

Camilo Torres reinterpretó las Escrituras a la luz de los postulados del Concilio Vaticano II con relación a la denominada causa social como pilar de la Iglesia Católica y enfatizó en la posición que debía asumir esa institución frente a las realidades del mundo39. Producto de la acción comunal y el contacto con diferentes cuadros de la Universidad Nacional, el sacerdote Torres se fue convenciendo de que "los cristianos tienen la obligación de participar en política y aun en la lucha armada" 40 y señaló como un imperativo cristiano optar por la revolución ${ }^{41}$ para poder cumplir con el mandato del amor eficaz ${ }^{42}$. Ese postulado, sirvió como guía para la vinculación de cristianos a las filas del ELN que buscaron seguir las huellas del primer sacerdote guerrillero de América Latina.

Tras morir en combate contra el Ejército de Colombia el 15 de febrero de 1966, fue reconocido dentro del ELN y otras organizaciones de América Latina, por haber asumido las consecuencias de la vida guerrillera, al entregar la vida por la causa de la revolución y la liberación. La muerte de Camilo Torres marcó un punto de inflexión en la historia del ELN43, desde ahí inició la construcción del héroe y prueba del impacto simbólico que representó lo corrobora el hecho de que varios sacerdotes, entre ellos Manuel Pérez decían querer ocupar su lugar.

Algunos biógrafos de Camilo Torres como Joe Broderick y Hildegart Luning, señalan como el sacerdote se veía a sí mismo como una figura mesiánica, como aquel capaz de alcanzar la salvación del pueblo mediante la entrega de su vida por la revolución. Para Broderick la impaciencia y actuar con ingenuidad, fueron lo que junto a "su temperamento impulsivo lo condujeron a un final prematuro" 44 . Dentro de la organización, la insistencia Camilo Torres en combatir como cualquier guerrillero raso, fue "interpretada por algunos como el sacrificio del redentor cristiano en estado de éxtasis" 45 y es lo que lo ubicó como un ícono venerable, en la medida en que según la organización "CAMILO, con su práctica, demuestra que es desde la Organización Revolucionaria de Vanguardia Político-Militar,

\footnotetext{
37 Ricardo Arias, El episcopado colombiano: intransigencia y laicidad 1850-2000, Bogotá, Universidad de los Andes, 2003, P. 198.

38 Eduardo Posada, La nación soñada, Bogotá, Norma, 2006.

39 Camilo Torres, Cristianismo y revolución, Ciudad de México, Ediciones Era, 1972

40 Andrea Pérez, "La memoria como constructora de sentido en la militancia: una mirada al componente simbólico del conflicto en Colombia", Boletín de Antropología, 31, 2016, 92-112.

41 Camilo Torres, Escritos políticos, Bogotá, Ancora Editores, 1991.

42 Ibidem.

43 Para un mayor análisis sobre las ideas políticas de Camilo Torres ves Orlando Villanueva, Camilo: pensamiento y proyecto político, Bogotá, Universidad Distrital Francisco José de Caldas, 2007.

44 Broderick, op. cit., P. 71.

45 Alejandro Sánchez, “Ciencia, Revolución y Creencia En Camilo Torres: ¿una Colombia Secular?”, Nómadas, 13, 2006, P. 249.
} 
desde donde debe jalonarse la Organización y la movilización de las masas" 46 , en oposición a las vías legales y reformistas, se hace una justificación a la rebelión.

Luning, también anota que cuando Camilo Torres decidió ingresar a las filas ELN, era consciente de las consecuencias que podría traerle el militar en una guerrilla, para la autora, se muerte "fue una consecuencia de su decisión de conciencia" 47 . Por el contrario, Broderick considera que "Camilo Torres había intentado lograr un cambio radical en las estructuras de poder por todos los medios democráticos a su alcance, solo cuando se le cerraron todas las puertas entre 1961 y 1963, terminó por simpatizar con los alzados en armas $^{48}$. Esa visión de Broderick, contrasta con la valoración que hace el ELN de Camilo, frente al proyecto de poder popular en el que exaltan su abstencionismo y el rechazo al reformismo, para dar paso a la revolución ${ }^{49}$.

La memoria que se recreó alrededor de Camilo Torres en el ELN está fuertemente relacionada con el imaginario del guerrero, que se enaltece en el plano heroico y mítico, de ahí la fuerza de la identidad de tales referentes como valor ejemplar para la vida de los combatientes que continúan luchando. En torno a la figura de Torres como un guerrerohéroe, se crearon pautas y principios de ser, de comportarse, de actuar, que se tradujeron en valores comunes, así como "la capacidad de entrega y sacrificio por los demás, tal como lo hace el guerrero-héroe" 50, estos elementos se desarrollaron en la I Asamblea Nacional Comandante Camilo Torres Restrepo y el II Congreso Unión Camilista Ejército de Liberación Nacional. En el ELN se dio la construcción del misticismo a partir de la práctica de valores comunes, lo cual llevó a la guerrilla según Medina a convertirse en una especie de secta mística y sacralizada ${ }^{51}$.

Camilo Torres Restrepo es un héroe dentro del ELN en la medida que marcó el camino que debían tomar los militantes de la organización guerrillera y en al ser considerado como el comandante que entregó la vida por la revolución. En una de las historias oficiales del ELN, Rojo y Negro, Milton Hernández militante de la organización, expresa que la muerte en combate de Camilo Torres,

No fue en vano, pasó a vivir eternamente en la memoria colectiva de un pueblo que no olvida y que permanece siempre presente en la lucha revolucionaria de cada instante. La grandiosa figura del Comandante en Jefe, Camilo Torres Restrepo, sigue y seguirá iluminando el camino de lucha de un pueblo que está dispuesto a luchar para que la próxima generación de colombianos no sea de esclavos ${ }^{52}$.

\footnotetext{
${ }^{46}$ Dirección Nacional del Ejército De Liberación Nacional [DN-ELN], op. cit., P. 164.

47 Hildegard Luning, Camilo Torres: sacerdocio y política, Bogotá, Universidad Nacional de Colombia, 2016, P. 158.

48 Broderick, op. cit.

49 Ver Dirección Nacional del Ejército De Liberación Nacional [DN-ELN], Asamblea Nacional Comandante Camilo Torres Restrepo. Simacota: Colombia Viva, 1986 y Dirección Nacional Unión Camilista Ejército de Liberación Nacional [DN-UCELN], Poder popular y nuevo gobierno. Conclusiones II Congreso, Simacota: Colombia Viva, 1989.

50 Pérez, op. cit., P. 72.

51 Medina, op. cit.

52 Milton Hernández, Rojo y Negro. Historia del ELN, Tafalla: Txalaparta, 2006, P. 134.
} 
Camilo Torres, es considerado dentro del ELN como un héroe de la revolución ${ }^{53}$ al ser un personaje excepcional, "sin que nadie le señalase la senda, Camilo cumplirá su opción por los pobres y por el proyecto de liberación nacional" 54. Para Bauzá con la muerte de aquel que es considerado héroe en una organización armada se da un proceso de configuración mística que deriva en la construcción de un "santo" en la memoria de la organización, cuya función es iluminar los caminos de la lucha55.

La motivación de tomar la vía armada como la base de una auténtica revolución llevó a Camilo Torres a expresar que "la lealtad revolucionaria tenía que estar acompañada por el sacrificio personal hasta las últimas consecuencias" 56 . Es la decisión de entrega, lo que lo inmortalizó como un héroe guerrillero, ya que, transitó un camino a la salvación a través de las acciones revolucionarias, que se expresan en el ELN mediante la muerte y no a través de triunfos militares o políticos.

El estatus y el reconocimiento de la figura de Camilo Torres, mostró un proceso de búsqueda de trascendencia dentro del ELN en cuanto se dio un proceso de emulación de las acciones y virtudes de Torres como un hombre nuevo digno de ser reconocido ${ }^{57}$. También se dio un proceso de imitación en la búsqueda de la trascendencia, una particularidad de ese proceso es que dejó de ser de naturaleza esencialmente religiosa y adquirió un carácter secular, "ahora «los hombres se convierten en dioses los unos para los otros» y la mediación externa se convierte en mediación «interna». [...] La imitación de Cristo se convierte en imitación del prójimo" 58 . En ese proceso de imitación,

Alrededor de la figura del guerrero-héroe, se crean pautas y principios de ser, de comportarse, de actuar, que se traducen en valores como los de la lealtad, el compromiso, el sentido de justicia y libertad, así como la capacidad de entrega y sacrificio por los demás, tal como lo hace el guerrero-héroe ${ }^{59}$.

Para Valencia, a partir de la consolidación del mito del primer sacerdote guerrillero de América Latina, el ELN “intenta rescatar la imagen perdida del sacerdote que alimentó su gesta insurgente en estos años dolorosos [...] La muerte de Camilo fue el sacrificio en el altar de un continente que había entrado en ebullición con la llegada triunfante de Castro en La Habana"60. Dentro del ELN el heroísmo está motivado por la búsqueda colectiva de un paraíso en la tierra que justifican la lucha armada61, así, el héroe es el que entregó su vida

\footnotetext{
53 Aguilera, op. cit.

54 Carlos Gómez, "Prólogo”, Camilo Torres, Camilo Torres. El pensamiento de un revolucionario, Bogotá, Ocean Sur, 2014, P. 2.

55 Hugo Bauzá, “El Mito del Héroe: morfología y semántica de la figura heroica”, Buenos Aires, Fondo de Cultura Económica, 1998.

56 Posada, op. cit., P. 239.

57 Esto es desarrollado en Casquete, “Religiones políticas y héroes patrios” y Carnovale, “Jugarse al Cristo: Mandatos, formas de sacralización y construcción identitaria en el PRT-ERP".

58 Garagalza, “René Girad y la paradoja de la modernidad”, Papers: Revista de Sociología, 114, 2007, P. 155.

59 Pérez, op. cit., P. 72.

60 Valencia, op. cit., P. 73.

${ }^{61}$ Andrea Pérez, Guerrilla y subjetividad: análisis antropológico del Ejército de Liberación Nacional de Colombia, Bogotá, Universidad Nacional de Colombia, 2018.
} 
de manera destacada y sobresaliente, aquel que, con las mejores características, el que menos merecía morir, se entregó por la lucha revolucionaria, según Pérez,

El mártir para el ELN hace alusión a la vida más sacrificada, a la vida más sublime, a la vida en medio de más sacrificio, donde llegan a los máximos niveles cualidades como la humildad, la fraternidad y el sacrificio [...]. Camilo Torres Restrepo para el ELN resume bien las categorías o términos de héroe y mártir62.

La violencia entonces puede generar figuras carismáticas 63 idóneas para ser convertidas en un mito y transformadas en un objeto de culto. La veneración que despierta aquél que da su vida por una causa puede ser "la versión secularizada del mártir caído por Dios"64, en el que la muerte es vista como un sacrificio, el cual fue el acto redentor de la comunidad por la que se murió, lo que genera que quién dio la vida sea recordado y la acción del sacrificio se grabe en la memoria colectiva de aquellos por los que dio la vida. En el caso del ELN, el mito de Camilo Torres se materializó en numerosos textos que lo referencian a través de fotos, frases y comunicados oficiales, de allí que se creó a su alrededor lo que Linz denomina sistema de creencias 65 , en la medida que se sacraliza su figura, los símbolos, lugares y las fechas en las que Torres participó y se crean rituales para enaltecer esos elementos.

Frente a la identidad cristiana del ELN, Aguilera señala como lo religioso presenta un ideal revolucionario que se manifiesta en la presencia de exsacerdotes dentro de sus filas, expresiones moralistas que rigen el comportamiento de los combatientes, como el rechazo al narcotráfico que "como empresa latinoamericana se ha convertido en elemento de identificación de la región y en especial de Colombia al llevar esta, el liderazgo en este siniestro negocio" 66 y el sentido sacrificial de las acciones emprendidas por la guerrilla, los cuales configuran la identidad del grupo y permitieron la creación de una moral de combate en la que se unieron el marxismo y el cristianismo.

La Asamblea Nacional Comandante Camilo Torres Restrepo y el II Congreso Unión Camilista Ejército de Liberación Nacional

La construcción de Camilo Torres como ícono del ELN se materializó en la I Asamblea del ELN, celebrada en marzo de 1986 que llevó por nombre Asamblea Nacional Comandante Camilo Torres Restrepo, en la que recogieron 22 años de lucha. En esta reunión se analizó por primera vez la relación entre el marxismo y el cristianismo, ya que como lo argumento el Comité Central de la organización "Con la participación de Camilo Torres

\footnotetext{
62 Pérez, op. cit., P. 108.

63 Iván Witker, “La conversión de terroristas en iconos o el síndrome de herostratos" Estudios Públicos 111, 2008, 151-171.

64 Jesús Casquete, “Religiones políticas y héroes patrios”, Papers: Revista de Sociología, 84, 2007, P. 131.

65 Juan Linz, “El uso religioso de la política y/o el uso político de la religión: la ideología-sucedáneo versus la religión-sucedáneo”, Reis: Revista Española de Investigaciones Sociológicas, 114, 2006, 11-35.

66 Dirección Nacional Unión Camilista Ejército de Liberación Nacional [DN-UCELN], op. cit., P. 215.
} 
Restrepo se inició prácticamente una característica popular como es la participación de los cristianos en la revolución" 67 , marcando un hilo conductor de la política de la guerrilla.

Uno de los elementos a considerar es como la figura de Camilo Torres no fue reivindicada en los primeros años tras su muerte, sino solo años después es reconocido como el eje articulador entre cristianos y marxistas, como comandante de la organización y como un ícono de la guerrilla en Colombia y América Latina. Al respecto en las entrevistas realizadas por Marta Harnecker a "Manuel Pérez, responsable político y primer responsable de la Organización; Nicolás Rodríguez Bautista (Gabino), responsable militar; Rafael Ortíz, miembro del Comando Central; Felipe Martínez, miembro de la Dirección Nacional”68, los milicianos señalan que

Cuando cae Camilo, la organización da una breve información en el periódico Insurrección. Debemos reconocer, sin embargo, que la dirección no se da cuenta de la verdadera dimensión del asunto. Consideramos que fue un gran error político el no haber desarrollado de inmediato la articulación entre el proyecto de Camilo y el ELN. La figura de Camilo fue siempre importante en la organización, pero sólo se levanta con fuerza a partir de 1977-78, cuando ya los movimientos revolucionarios más avanzados de América Latina están demostrando la importancia de la participación de los cristianos, sobre todo en América Central. Las comunidades de base de El Salvador, la participación de cristianos en la revolución sandinista... Además, muchos sacerdotes, monjas, laicos simpatizaban y desarrollaban un trabajo, un proselitismo orientado hacia el ELN, aunque no estuvieran vinculados orgánicamente, recuerda que por ese tiempo nuestra organización estaba en crisis. Luego, cuando fuimos contactando y organizando a muchos de esos compañeros, quienes aportaban un buen trabajo de organización barrial, nos dimos cuenta que detrás de muchos de esos trabajos estaban las ideas de Camilo. De otro lado, el ELN se propone retomar, dinamizar y proyectar a Camilo, no solamente en el espacio de la religiosidad popular, o sea, en el movimiento de comunidades eclesiales de base, para nosotros Camilo tiene una mayor dimensión, no sólo nacional sino continental. Partimos de la premisa de que es un precursor de los cristianos revolucionarios en América Latina y pensamos que es un aporte a la identidad nacional, porque Camilo aportó no solamente como sacerdote sino como revolucionario. Sus investigaciones, sus estudios, su conducción del Frente Unido, su vida guerrillera, va más allá del mero sacerdocio. Y por eso, para nosotros, Camilo es nuestro comandante en jefe ${ }^{69}$.

La construcción de la figura de Camilo Torres dentro del ELN se consolidó en la I Asamblea Nacional Comandante Camilo Torres Restrepo, en la que se planteó al Camilismo como el punto de encuentro entre marxistas y cristianos en la medida que

Con la noción de "AMOR EFICAZ", Camilo abre las puertas a la participación de los Cristianos en la lucha revolucionaria. En esta noción Camilista del "AMOR EFICAZ" encontramos sintetizada la visión del

${ }^{67}$ Dirección Nacional del Ejército De Liberación Nacional [DN-ELN], Asamblea Nacional Comandante Camilo Torres Restrepo, Simacota, Colombia Viva, 1986, P. 5.

68 Harnecker, op. cit., P. 1.

69 Rafael Ortíz y Felipe Martínez en Harnecker, op. cit., P. 6 
Cristianismo que se entrega hasta la muerte por la Liberación del Pueblo. El mismo CAMILO en su "MENSAJE A LOS CRISTIANOS" dice: "La revolución no solo es permitida, sino obligatoria para los Cristianos que ven en ella la única manera eficaz y amplia de realizar el amor... para todos"70

La participación de Camilo Torres en el Frente Unido, como movimiento que abogaba por la abstención, sirvió para que en la I Asamblea se justificara la revolución, en la medida en que esa postura ante las elecciones "reivindica la lucha armada como el único camino para la Construcción del poder Revolucionario"71.

Dentro del ELN, luego de su muerte en combate y a partir de la Asamblea Nacional que lleva su nombre, se realizó una recreación simbólica de la figura de Camilo Torres como líder de la organización al conferirle el máximo grado dentro de la estructura guerrillera: Comandante en jefe, de manera póstuma72. También se reconoció el Camilismo como elemento central de la identidad nacional promovida por el ELN y fundamental para el movimiento revolucionario de masas que buscaba alcanzar el grupo armado.

El sentido de trascendencia y la necesidad de imitar a aquellos que cumplen con las características del sacrificio hace que, dentro del ELN, se haya generado una veneración la persona de Camilo Torres por ser la primera figura reconocida a nivel nacional como sacerdote que perdió la vida en un combate dentro de una organización marxista.

La tercera estrofa del Himno del ELN pone a Camilo Torres como ejemplo de entrega, por vivir la consigna de la organización:

Avancemos al combate compañeros

Que están vivas la conciencia y la razón

De Camilo el Comandante Guerrillero

Con su ejemplo en la consigna NUPALOM ${ }^{73}$

(Ni un Paso Atrás, Liberación o Muerte) ${ }^{74}$.

En el escudo de la organización las ideas 6 y 8, presentan el heroísmo y la entrega como elementos guía de la lucha armada. En la idea 6 De liberación nacional y construcción del socialismo, el ELN describe como "el horizonte es de color rojo lo cual indica nuestra decisión de luchar por la libertad de Colombia y América Latina, bajo el ejemplo de nuestro héroes y mártires"75, el punto 8 , referente al principio de lucha expone que

Todas las ideas del escudo están envueltas en un compromiso de principio del E.L.N., el cual arranca del ejemplo histórico de José Antonio Galán, para plantearnos ir hasta las últimas consecuencias por los ideales

\footnotetext{
70 Dirección Nacional del Ejército De Liberación Nacional [DN-ELN], op. cit., P 165.

71 Ibid., 164.

72 Ver en Aguilera, op. cit., y Dirección Nacional del Ejército De Liberación Nacional [DN-ELN], op. cit., P. 5.

73 Dirección Nacional del Ejército De Liberación Nacional [DN-ELN], op. cit., P. 194.

74 Paréntesis explicativo añadido por el autor

75 Dirección Nacional del Ejército De Liberación Nacional [DN-ELN], op. cit., P. 194
} 
revolucionarios. Tiene entonces el escudo inscrita nuestra consigna: ¡NI UN PASO ATRÁS LIBERACIÓN O MUERTE!76.

En el himno de la agrupación, es exaltado como comandante, la fecha de su muerte, 15 de febrero, hace parte de las conmemoraciones oficiales de la agrupación y existe dentro del ELN la Orden Camilo Torres77, que se entrega a guerrilleros destacados por seguir eficazmente los pasos del héroe caído en la construcción de la revolución.

En la I Asamblea, se institucionalizó el culto a los caídos en combate, a partir de la explicación de los símbolos de los elenos, que representan un proceso de mistificación de Camilo Torres y trazaron una ruta para los combatientes que siguieron el ejemplo del sacerdote guerrillero, según Pérez eso derivó en la creación de un ejército de caídos por los cuales se debe continuar en la lucha ${ }^{78}$.

En el ELN, a partir de la muerte de Camilo Torres se representó una ritualización del mito de salvación del cristianismo y sirvió para otorgarle a aquellos que siguieron sus pasos "una aureola de sacralidad dimensionada en dos papeles transcendentales: el de salvadores, en vida, y el de mártires, después de la muerte"79. Cassirer expone que ese proceso de creación de personajes que puedan ser adorados se da por la necesidad de que existan figuras míticas y venerables dentro de las agrupaciones humanas, ya que "sin estos santos temporales, [...] no podríamos vivir" 80 .

En consecuencia, apelar a la memoria como mecanismo de reactivación y normalización de los ritos es un elemento que permite configurar el proyecto de los elenos. Manuel Pérez, comandante del ELN a partir de 1974 señala que "desde el momento en que supo que Camilo había muerto, lo asumió como algo propio, una especie de norte en su vida. Representaba la meta más sublime, el hombre que se había "encarnado" de verdad, Camilo selló aquel compromiso con lo único valedero, su propia sangre" 81 . La muerte de Torres y la fuerza de ese acontecimiento como mito se valida, actualiza y exalta mediante el culto a los demás caídos y sirve además como elemento para validar y legitimar la lucha armada, como se ve en los símbolos del ELN y en su proclamación en el marco de la I Asamblea.

Alrededor de la muerte de Camilo Torres en 1966, se generó lo que Aguilera denomina un culto guerrillero, el cual, "es ante todo un culto a héroes guerreros vivificados con la muerte" 82 , aquellos hombres que murieron en combate adquieren características de hombres nuevos y potenciales mártires ${ }^{83}$. Dentro de la organización guerrillera, la figura de Torres sufrió una transformación en la que el sacerdote dejó ser una víctima de la violencia

\footnotetext{
76 Ibidem.

77 Mario Aguilera, "ELN entre las armas y la política”, Gonzalo Sánchez, María Wills y Francisco Gutiérrez (coord.), Nuestra guerra sin nombre: transformaciones del conflicto en Colombia, Bogotá, Grupo Editorial Norma, 2006, 209-266.

78 Andrea Pérez, "La presencia de lo religioso en la militancia revolucionaria”, Análisis Político, 26, 2013, $27-43$.

79 Pérez, op. cit., P. 32.

80 Ernst Cassirer, El mito del Estado, Ciudad de México, Fondo de Cultura Económica, 1947, P. 226.

81 Broderick, op. cit., P. 75.

82 Aguilera, op. cit., P. 24.

83 Se puede ver en Arias, “El episcopado colombiano en los años 1960” y Vezzetti, Sobre la violencia revolucionaria. Memorias y olvidos.
} 
institucional y se convirtió en un héroe. Su muerte lo posicionó como aquel Hombre Nuevo que se sacrificó por defender la revolución, y lo consolidó como el estandarte de los elenos ${ }^{84}$, generando que, se consumara la relación entre la violencia, el sacrificio y el heroísmo dentro de las filas del ELN.

En las conclusiones del II Congreso Unión Camilista Ejército de Liberación Nacional publicadas en 1990, se plantea el cristianismo revolucionario como elemento central para entender el proyecto insurreccional que necesita Colombia y que busca liderar el ELN, siguiendo la línea de lo presentado en 1986 en la I Asamblea, exaltando la figura de Camilo Torres no solo dentro de la organización, sino como un símbolo de lucha en América Latina y como una muestra de la necesidad de una unión entre cristianos y marxistas para lograr la revolución, en palabras de la Dirección Nacional Unión Camilsta Ejército de Liberación Nacional, con la unión

Se abre la nueva dimensión de los cristianos revolucionarios, desde las revoluciones centroamericanas se comprueba que se puede construir la nueva sociedad con la participación activa de los cristianos. En el Poder Popular se hace presente para los cristianos el Reino de Dios. Se va descubriendo que América Latina no está dividida entre cristianos y marxistas, sino entre revolucionarios y defensores del sistema capitalista ${ }^{85}$.

Para Vezzetti, en las revoluciones latinoamericanas se extendió la concepción de que "la liberación dependía de la creación de un hombre nuevo" 86 , aquel sujeto capaz de llevar a cabo la gesta revolucionaria y de ser el fundador del nuevo mundo, una nueva historia y un nuevo paraíso en la tierra. En esa figura, se da un sincretismo entre el marxismo y el cristianismo, en cuanto se toman elementos como el sacrifico y el martirio para exaltar la labor de ese nuevo hombre como sujeto central de la revolución, Camilo Torres, se puede considerar un ejemplo de Hombre nuevo dentro de las filas del ELN, que debe ser imitado por más cristianos, señalando que

La fe está fundamentada en la esperanza de un mundo de amor sin explotación y ese compromiso es la forma concreta que asume para ellos el amor, la fe se da por la "fuerza del amor" al hombre. El amor al hombre está enmarcado en la perspectiva de superar la explotación milenaria de los pobres y construir el "Hombre Nuevo" que rompa el individualismo y el egoísmo, que se vive en función del servicio de los demás. Este "Hombre Nuevo" es el hombre de una sociedad socialista en la que el hombre ya no explota al hombre ${ }^{87}$.

También en el II Congreso, se retoman los postulados del Concilio Vaticano II, las conclusiones de la Conferencia Episcopal Latinoamericana de 1968, la Carta a los Obispos

\footnotetext{
84 León Valencia, Gente que conocí, Bogotá, Taller de Edición, 2007.

${ }^{85}$ Dirección Nacional Unión Camilista Ejército de Liberación Nacional [DN-UCELN], op. cit., P. 223.

86 Hugo Vezzetti, Sobre la violencia revolucionaria. Memorias y olvidos, Buenos Aires, Siglo XXI Editores, 2009 , P. 173.

87 Dirección Nacional Unión Camilista Ejército de Liberación Nacional [DN-UCELN], op. cit., P. 227.
} 
de América Latina y los postulados de otros movimientos como el grupo Golconda y Sacerdotes para América Latina, con relación a la existencia de dos Iglesias, las condiciones de violencia que sufren los menos favorecidos en la región y la necesidad de transformar la realidad social. El ELN tomando como base esos pronunciamientos, concluyó que era posible e incluso necesaria la unión entre marxistas y cristianos para lograr la revolución,

La Unión Camilista Ejército de Liberación Nacional, tiene una rica experiencia, pues siempre ha estado abierta, siendo Organización marxistaleninistas, a la participación de cristianos revolucionarios. Primero fue Camilo, posteriormente algunos sacerdotes de Golconda, SAL y religiosos de otros movimientos cristianos, e incluso frente guerrilleros han surgido a partir de trabajos cristianos de base. Eso ha permitido un desarrollo político sobre este aspecto de la práctica y fruto del tratamiento a las contradicciones políticas que este fenómeno genera a su interior ${ }^{88}$.

\section{Conclusiones}

En las conclusiones de la I Asamblea Nacional Comandante Camilo Torres Restrepo y el II Congreso Unión Camilista Ejército de Liberación Nacional, se da la consolidación oficial desde la institucionalidad del ELN de la unión entre el marxismo y el cristianismo, a través de la exaltación de Camilo Torres Restrepo, como un ícono que recoge en su figura la mistificación de la muerte y los elementos de la tradición cristiana y marxista.

Sin embargo, a pesar de que con la figura de Camilo Torres se pretende recrear la visión cristiana del sacrificio en los últimos años de la década de los ochenta y así unir dos corrientes ideológicas consideradas antagónicas, los elementos cristianos dentro del ELN no resultan una característica homogénea en todas las etapas de la organización guerrillera que se define como marxista y atea en los últimos años y deja de lado el elemento cristiano resaltado en los primeros dos Congresos. Lo cristiano en las filas del ELN surge de un hibrido entre la identidad de los militantes campesinos de mayoría católica y de la influencia de la incorporación en sus filas de exsacerdotes como Torres, Manuel Pérez, Domingo Laín y José Antonio Jiménez. También, la influencia proveniente de las imágenes de los íconos marxistas como Ernesto Guevara convertido en una figura de culto casi religioso le otorgan un aire de religiosidad a las acciones de los elenos en la que dar la vida por la revolución es un signo de trascendencia y heroísmo, y no un asunto meramente humano.

En consecuencia, la unión entre el marxismo y el cristianismo en el periodo de 1986 a 1989 dentro del ELN, se vio a través de la mística desarrollada en torno a la muerte de Camilo Torres Restrepo considerada como un sacrificio, que ha sirvió como elemento discursivo de justificación de la violencia y se utilizó como un discurso para el llamado a los cristianos a integrar las filas de la organización revolucionaria. Adicionalmente, la carga ideológica que se pone sobre los caídos y el culto que se les rinde es un elemento que ha permitido la cohesión de la tropa y tendió a superar el debate entre marxismo y cristianismo dentro del ELN, consolidando su unión en los dos primeros Congresos.

88 Dirección Nacional Unión Camilista Ejército de Liberación Nacional [DN-UCELN], op. cit., P. 227. 
A pesar del aumento en la literatura sobre el Ejército de Liberación Nacional y los abundantes estudios sobre Camilo Torres aún queda por hacer una revisión de lo religioso dentro de las filas del ELN en la que se tenga como base fuentes primarias y acceso a la información proveniente de un trabajo de campo con integrantes de la organización, eso podrá contribuir a entender las diferencias entre bloques con respecto a la religión y el papel de la Iglesia Católica en los intentos de paz que se han adelantado entre el gobierno de Colombia y la insurgencia.

\section{Referencias bibliográficas}

\section{Libros y capítulos de libros}

Mario Aguilera, "ELN entre las armas y la política”, Gonzalo Sánchez, María Wills y Francisco Gutiérrez (coord.), Nuestra guerra sin nombre: transformaciones del conflicto en Colombia, Bogotá, Grupo Editorial Norma, 2006, 209-266.

Ricardo Arias, El episcopado colombiano: intransigencia y laicidad 1850-2000, Bogotá, Universidad de los Andes, 2003.

Gilles Bataillon, "Ernesto Guevara: Héroe revolucionario y apologista del poder ególatra", Marco Estrada y Gilles Bataillon, Cruzadas seculares: religión y luchas (anti) revolucionarias, Ciudad de México, Colegio de México, 2012, 161-194.

Jean-Pierre Bastian, "Cruzadas seculares: imaginario religioso y luchas revolucionarias en América Latina", Marco Estrada y Gilles Bataillon, Cruzadas seculares: religión y luchas (anti) revolucionarias, Ciudad de México, Colegio de México, 2012, 17-34.

Hugo Bauzá, El Mito del Héroe: morfología y semántica de la figura heroica, Buenos Aires, Fondo de Cultura Económica, 1998.

Joe Broderick, Camilo Torres. El cura guerrillero, Bogotá, Círculo de lectores, 1977.

Joe Broderick, El guerrillero invisible, Bogotá, Intermedio, 2000.

Ernst Cassirer, El mito del Estado, Ciudad de México, Fondo de Cultura Económica, 1947.

Marco Estrada y Gilles Bataillon, (ed.), Cruzadas seculares: religión y luchas (anti) revolucionarias, Ciudad de México, Colegio de México, 2012.

Marco Estrada, "Del apocalipsis al fin de la historia: Los agentes de pastoral y el EZLN en Chiapas", Marco Estrada y Gilles Bataillon, Cruzadas seculares: religión y luchas (anti) revolucionarias, Ciudad de México, Colegio de México, 2012, 55-84.

Anaité Galeotti, “Un Jesús muy compañero. Un testimonio de liberación”, Marco Estrada y Gilles Bataillon, Cruzadas seculares: religión y luchas (anti) revolucionarias, Ciudad de México, Colegio de México, 2012, 85-102.

Carlos Gómez, "Prólogo", Camilo Torres, Camilo Torres. El pensamiento de un revolucionario, Bogotá, Ocean Sur, 2014, 2-10.

Germán Guzmán, La violencia en Colombia: Parte descriptiva, Cali, Ediciones el progreso, 1968. Marta Harnecker, ELN: Unidad que multiplica, La Habana, Banco Popular, 1988.

Milton Hernández, Rojo y Negro. Historia del ELN, Tafalla, Txalaparta, 2006.

María López, Camilo camina en Colombia, Navarra, Txalaparta, 1990

Hildegard Luning, Camilo Torres: sacerdocio y política, Bogotá, Universidad Nacional de Colombia, 2016. 
Carlos Medina, ELN: una historia contada a dos voces, entrevista con el cura Manuel Pérez y Nicolás Rodríguez Bautista, Gabino, Bogotá, Rodríguez Quito, 1996.

Carlos Medina, "Aproximación a las ideas políticas del ELN", Corporación Observatorio para la Paz, Las verdaderas intenciones del ELN, Bogotá, Intermedio Editores, 2001, 120157.

Carlos Medina, Conflicto armado y procesos de paz en Colombia: memoria casos FARC-EP y ELN, Bogotá, Universidad Nacional de Colombia, 2009.

Carlos Medina, ELN: Ejército de Liberación Nacional: cincuenta años de lucha armada, Bogotá, Universidad Nacional de Colombia, 2014.

Carlos Medina, Camilo Torres Restrepo: la sonrisa de la esperanza, Bogotá, Universidad Nacional de Colombia, 2017.

Carlos Medina, Ejército de Liberación Nacional (ELN): Historia de Las Ideas Políticas (1958-2018), Bogotá, Universidad Nacional de Colombia, 2019.

Andrea Pérez, Guerrilla y subjetividad: análisis antropológico del Ejército de Liberación Nacional de Colombia, Bogotá, Universidad Nacional de Colombia, 2018.

Eduardo Posada, La nación soñada, Bogotá, Norma, 2006.

Malik Tahar, "Una expresión cristiana del radicalismo sociopolítico en América Latina: La teología de la liberación entre cruzada antisacrificial y el sacrificio crístico", Marco Estrada y Gilles Bataillon, Cruzadas seculares: religión y luchas (anti) revolucionarias, Ciudad de México, Colegio de México, 2012, 35-54.

Álvaro Tirado, Los años sesenta, Bogotá, Debate, 2014.

Camilo Torres, Cristianismo y revolución, Ciudad de México, Ediciones Era, 1972.

Camilo Torres, Escritos políticos, Bogotá, Ancora Editores, 1991.

Alejo Vargas, "Anotaciones sobre el discurso ideológico y político del ELN", Corporación Observatorio para la Paz, Las verdaderas intenciones del ELN, Bogotá, Intermedio Editores, 2001, 72-83.

Alejo Vargas, Guerra o solución negociada. ELN: origen, evolución y procesos de paz, Bogotá, Intermedio, 2006.

León Valencia, Gente que conocí, Bogotá, Taller de Edición, 2007.

Hugo Vezzetti, Sobre la violencia revolucionaria. Memorias y olvidos, Buenos Aires, Siglo XXI Editores, 2009.

Orlando Villanueva, Camilo: pensamiento y proyecto político, Bogotá, Universidad Distrital Francisco José de Caldas, 2007.

\section{Artículos}

Mario Aguilera, "La memoria y los héroes guerrilleros", Análisis Político, 49, 2003, 3-27.

Ricardo Arias, "El episcopado colombiano en los años 1960", Revista de Estudios Sociales 33, 2009, 79-90. Disponible en

https:/ / doaj.org/article/ab0091cd5dfa4649ae22a642e85bca5f

Jesús Casquete, "Religiones políticas y héroes patrios", Papers: Revista de Sociología, 84, 2007, 129-138. DOI: http:// doi.org/10.5565/rev/papers/v84n0.1676

Vera Carnovale, "Jugarse al Cristo: Mandatos, formas de sacralización y construcción identitaria en el PRT-ERP", Entrepasados, 28, 2005, 11-26. Disponible en 
http:/ / laptoc.library.vanderbilt.edu/query/content_result.jsp?format=4\&journal_i d=2902\&issue_id=35071

Víctor Codina, "Teología de la liberación 40 años después. balance y perspectiva”, Revista de Estudios de Teologia E Ciências Da Religião, 11, 2013, 1357-1377. DOI: https://doi.10.5752/P.2175-5841.2013v11n32p1357

Luis Garagalza, "René Girad y la paradoja de la modernidad”, Papers: Revista de Sociología, 114, 2007, 149-156. DOI: http://dx.doi.org/10.5565/rev/papers/v84n0.1678

Juan Linz, "El uso religioso de la política y/o el uso político de la religión: la ideologíasucedáneo versus la religión-sucedáneo", Reis: Revista Española de Investigaciones Sociológicas, 114, 2006, 11-35. DOI: https:/ / doi.org/10.2307/40184736

Oscar Pedraza, "El ejercicio de la liberación nacional: ética y recursos naturales en el ELN", Controversia, 190, 2008, 197-241. Disponible en

http:/ / bibliotecavirtual.clacso.org.ar/Colombia/cinep/20100926015601/elejercidiodelalib eracion.pdf

Andrea Pérez, "La memoria como constructora de sentido en la militancia: una mirada al componente simbólico del conflicto en Colombia", Boletín de Antropología, 31, 2016, 92-112. DOI: https:/ / doi.org/10.17533/udea.boan.v31n51a05

Andrea Pérez, "La presencia de lo religioso en la militancia revolucionaria", Análisis Político, 26, 2013, 27-43.

Andrea Pérez, "Tradiciones de Resistencia y Lucha: Un análisis sobre el surgimiento y la permanencia de las guerrillas en Colombia", Análisis Politico, 23, 2010, 63-80.

Victorino Pérez, "Richard Shaull, Camilo Torres, Rafael Ávila, "Golconda", Sacerdotes para América Latina, Cristianos por el Socialismo y Comunidades Eclesiales de Base", Cuestiones Teológicas, 43, 2016, 73-108. DOI: http:/ / dx.doi.org/10.18566/ cueteo.v43n99.a04

Alejandro Sánchez, “Ciencia, Revolución y Creencia En Camilo Torres: ¿una Colombia Secular?", Nómadas, 13, 2006, 241 -258.

Alejo Vargas, "Conflicto armado, su superación y modernización en la sociedad colombiana", Pensamiento jurídico, 26, 2009, 161-180.

Iván Witker, "La conversión de terroristas en iconos o el síndrome de herostratos" Estudios Públicos, 111, 2008, 151-171. Disponible en

http://dialnet.unirioja.es/servlet/ oaiart?codigo=2907921

\section{Prensa}

Joe Broderick, "El cura guerrillero." Revista Semana, 12 de noviembre de 1980, http:/ / www.semana.com/especiales/articulo/el-cura-guerrillero/60097-3

(consultado el 6 de octubre de 2018)

Obispos del Tercer Mundo, “Carta a los Obispos de América Latina.” Juan García (dir.), Cristianismo y Revolución, Buenos Aires, Ediciones E.S.E, 1965, 70-71 


\section{Entrevistas}

Entrevista a Javier Darío Restrepo, 25 de enero de 2017.

\section{Documentos privados del Ejército de Liberación Nacional}

Dirección Nacional del Ejército De Liberación Nacional [DN-ELN], Asamblea Nacional Comandante Camilo Torres Restrepo. Simacota: Colombia Viva, 1986.

Dirección Nacional Unión Camilista Ejército de Liberación Nacional [DN-UCELN], Poder popular y nuevo gobierno. Conclusiones II Congreso, Simacota: Colombia Viva, 1989. 